\title{
SER E VIVER ENQUANTO COMUNIDADES TRADICIONAIS
}

\author{
Be and live as the traditional community
}

Angela Fagna Gomes de Souza*

Carlos Rodrigues Brandão**

\begin{abstract}
Resumo
Esta pesquisa foi realizada a partir da análise documental de fontes primárias encontradas em arquivos No presente artigo temos a intenção de fazer uma reflexão teórica acerca de algumas leituras sobre Comunidades Tradicionais. Na primeira parte do texto apresentamos as concepções fundantes dos estudos sobre comunidades, relacionados aos fatores de ordem conceitual e tempo/espacial. Em seguida, mencionamos os desdobramentos destes comportamentos dentro do mundo vivido em comunidade, associados às relações simbólicas e de afetividade. E finalmente, enfocamos a diversidade conceitual sobre a categoria comunidade tradicional, com a intenção de priorizar as singularidades comportamentais de cada localidade. Este complexo envolvendo as relações sociais, políticas, econômicas, religiosas e culturais nos permite formas variadas de trabalhar o conceito não de forma fragmentada, mas sim, integrada, produzindo "lógicas diferenciadas" envolvidas por um saber característico de cada local estudado. Com este olhar múltiplo, é possível observar os gestos, comportamentos e as condutas sociais de um lugar e de um povo. The observation of everyday actions can tell a lot about how people think about the world they live.
\end{abstract}

Palavras-chave: Comunidades tradicionais, Vivido, Relações sociais, Diversidade.

\section{Abstract}

In this paper is a theoretical reflection on Traditional Communities. In the first part of the text presents the fundamental concepts of studies on traditional communities, factors relating to its conceptual and time space. Then mention the reflections of social behavior in the context of life in communities, associated with symbolic and affective relations. Finally, we address the conceptual diversity of the traditional community category, with the intention to prioritize the singularities of each locality. This complex scenario involving the social, political, economic, religious and cultural enables us to obtain various forms of work with this concept in an integrated fashion, unveiling the "differentiated logics" of knowledge that characterizes each place. From this multiple look, we can see the gestures, behaviors and social behaviors of a people in their place. The observation of everyday actions can tell a lot about how people think about the world they live.
\end{abstract}

Key words: Traditional community, Lived, Relations social, Diversity.

\begin{abstract}
Resumen
En este artículo se pretende hacer una reflexión teórica acerca de algunas lecturas en las comunidades tradicionales. En la primera parte del texto se presenta los conceptos fundamentales de los estudios comunitarios, los factores relacionados con el orden conceptual y el tiempo / espacio. Luego menciona las consecuencias de estos comportamientos en el mundo vivían en la comunidad, asociados a las relaciones simbólicas y afecto. Y, por último, nos centramos en la diversidad conceptual de la categoría de la comunidad tradicional, con la intención de dar prioridad a las peculiaridades de comportamiento de cada localidad. Este complejo que implica la política social, económica, cultural y religiosa que permite diversas formas de la idea no funciona poco a poco, pero integrada, la producción de "lógica diferencial" que participan en una característica del conocimiento de cada sitio de estudio. Con esta mirada múltiple, se puede ver los gestos, las actitudes y el comportamiento social de un lugar y un pueblo. Las acciones cotidianas dicen mucho acerca de cómo piensa la gente de la comunidad mundial en la que viven.
\end{abstract}

Palabras-clave: Comunidades tradicionales, Vivido, Relaciones socials, Diversidad.

(*) Doutoranda em Geografia pela Universidade Federal de Uberlândia - Rua A, n: 13 A, Bairro: Aeroporto - CEP: 49037-599 Aracaju (SE), Brasil, Tel: (+ 55 79) 91514809 - angelafagna@hotmail.com

(**) Professor Visitante da Universidade Federal de Uberlândia - Av. João Naves de Ávila, 2121 - Bloco H Sala 1H 35 CEP 38408-100 - Uberlândia (MG), Brasil, Tel/Fax (+ 55 34) 3239 4381/3239 4169 - Ramal 39 - carlosrbrandão@yahoo.com.br 


\section{INTRODUÇÃO}

O presente artigo tem a intenção de fazer uma reflexão teórica acerca do conceito de comunidades tradicionais. Abordamos a articulação entre algumas concepções de análise relacionadas à sociologia, a antropologia e a Geografia, procurando refletir como aplicá-las de acordo com suas funcionalidades e representatividades.

Para entender as diversas formas de abordar esta temática, são necessárias reflexões de pesquisadores que nos proporcionem saberes diferenciados, compreendo que o "ser pesquisador" encontra-se a cada dia motivado por novos ensinamentos e por perspectivas teórico-metodológicas contínuas.

A questão inicial a que nos propomos neste trabalho nos instiga a refletir sobre a seguinte indagação: o que caracteriza uma comunidade tradicional? A resposta a esta pergunta traz uma série de análises que vão desde os fatos mais genéricos e uniformes presentes em cada uma delas, até os comportamentos mais específicos de um dado lugar.

Para alguns autores que trabalham com comunidade tradicional, o essencial é diferenciar e desvendar o que cada local pesquisado tem de singular. O pesquisador precisa, antes de tudo, saber captar o que "eles dizem sobre eles" para, só então, reconstruir o que "nós dizemos sobre eles", numa criação que parte do "endo" (de dentro da comunidade) para o "exo" (construção do pesquisador). A palavra "camponês", por exemplo, não é utilizada pelas pessoas que vivem no campo, mas, é sim, antes de tudo, uma categorização adotada por pesquisadores e cientistas, sendo, portanto, construída pelos "de fora". Já outras como "caboclo" e "ribeirinho" foram criadas pelos que vivem e convivem com os ambientes e comunidades específicas desses povos, ou seja, "eles" criaram seus próprios "nomes", portanto, os próprios "sujeitos sociais" dizem quem são e criam categorias distintivas internas e especificas de seu modo de vida.

Neste sentido, a percepção e o olhar de cada pesquisador ditam a forma como será categorizada uma pesquisa e de como o real, como modo de vida concreto, será traduzido. Ao se chegar pela primeira vez em uma comunidade em uma situação de pesquisa, busca-se inicialmente, "o ver" com um momento/etapa de olhar inocente, capturando gestos, cenas e coisas. Posteriormente, já seria possível perceber "o outro" como uma conduta social, uma interação intermediada por códigos e linguagem. E, em uma aproximação mais íntima, será capaz de trocar mensagens e manter laços de reciprocidade.

Todas estas ações de "chegada" e "estadia" de um pesquisador em uma determinada comunidade desvendam de que forma um dado local pode ser caracterizado como uma comunidade tradicional. Observar os gestos, os comportamentos e as condutas sociais de um povo em um lugar, revela muito sobre o que eles são e de que forma eles pensam o mundo. As relações simbólicas e de afetividade, por exemplo, é um fator presente em quase todos os estudos sobre comunidades tradicionais, já as formas de ocupação e usos dos espaços são específicas de cada localidade.

Sendo assim, organizamos o texto da seguinte forma: na primeira parte apresentamos as concepções fundantes dos estudos sobre comunidades, relacionados aos fatores de ordem conceitual e tempo/espacial. Em seguida, mencionamos os desdobramentos destes comportamentos dentro do mundo vivido em comunidade, associado às relações sociais, simbólicas e de afetividade. E finalmente, trabalhamos de maneira dinâmica e articulada, enfocando a diversidade conceitual sobre a categoria comunidade tradicional, com a intenção de priorizar as singularidades comportamentais de cada localidade.

\section{O CONCEITO DE COMUNIDADE E SEUS ESPAÇOS}

O que caracteriza estar na comunidade e viver em comunidade nos diversos lugares? Na intenção de responder a esta pergunta, partimos primeiramente para a análise do conceito de comunidade. Desde um indivíduo até suas múltiplas relações, as formas de viver em e na comunidade são esta- 
belecidas por uma rede de relações sociais interativas, constituídas por um modo de vida próprio. Algo passado, vivido e pensado entre e através de atores sociais e em um determinado tempo-espaço.

Fundamentamos esta indagação com a leitura de autores como Tonnies, MacIver e Page, Freyer Weber e Park e Burgess que empregam as expressões comunidade e sociedade de forma correspondente, sendo dois aspectos essenciais de toda a vida grupal.

Autores como MacIver e Page (1973, p. 123) afirmam que "uma comunidade ocupa sempre uma área territorial". Mas, é possível existir uma comunidade sem as suas bases territoriais? Os autores indicam que não necessariamente deva existir um espaço geográfico determinado, como um território controlado, para que uma comunidade exista de fato.

Onde quer que os membros de qualquer grupo, pequeno ou grande, vivam juntos e de modo tal que partilhem, não deste ou daquele interesse, mas das condições básicas de uma vida em comum, chamamos a esse grupo comunidade. (MACIVER, 1973, p. 122).

As comunidades podem ocupar um lugar, uma determinada localidade onde estabelecem apenas laços de solidariedade. As relações sociais dão características de vínculos e afeição com o lugar de existência. Os viventes deste lugar constroem laços interativos de afetividade, considerando o território como uso, apropriação, afeições e símbolos característicos de um espaço heterogêneo.

Conforme afirmam MacIver e Page (1973, p. 122), a vida em comunidade "pode ser totalmente vivida dentro dela", não sendo necessariamente auto-suficientes. O que importa realmente são os interesses em comum, ou seja, o sentimento de comunidade, ou como prefere Weber (1973, p. 142) "o sentido de formar um todo".

Já Wirth (1973, p. 85) conceitua comunidade como "o viver-se juntos, de um lado, e o de participar-se de uma vida em comum de outro". O que interessa, neste caso, é a participação coletiva dos indivíduos, os domínios sociais e a representatividade própria de cada sujeito. Assim, estes fatos conduzem a um espaço com características peculiares de vivências e formas singulares de agir, pensar, habitar e viver em/na comunidade.

O habitar neste caso, é o elemento que conduz a territorialização da comunidade. Em outras palavras, significa afirmar que é estabelecendo teias sociais e bases territoriais, entendidas aqui como recurso necessário a vida cotidiana e, ao mesmo tempo como a base significante de cada comunidade, construídas e (re) construídas geograficamente.

A comunidade é, portanto um "espaço de vida". O que caracteriza a essência de cada comunidade são os sujeitos e as relações que se estabelecem entre eles e com a natureza. Ramos (2009, p. 8) sintetiza o conceito da seguinte forma:

[...] três aspectos são fundamentais para conceituarmos os espaços da comunidade: primeiro, a comunidade é um espaço da vida na cotidianidade; segundo, o que está dentro da comunidade são pessoas e suas relações; finalmente, o que caracteriza a comunidade é o fato de que a vida de alguém pode ser totalmente vivida dentro dela.

Portanto, a constituição da vida em comunidade depende das inter-relações sociais ligadas a um território comum. Território este, não essencialmente os limites geográficos de habitação, mas ainda os universos que se expandem para além do espaço delimitado. Compreende os ambientes simbólicos, místicos, políticos e econômicos. O território neste caso é dinâmico, os limites e as fronteiras perdem as suas características principais, dando lugar para a referência significativa na vida das pessoas.

Além do território, percebemos ainda o sentimento de afetividade presente na vida comunitária. São laços de reciprocidade, onde o viver juntos em um mesmo lugar, a união e a "área de vida em comum" faz de um dado lugar uma comunidade, em que é garantida a sobrevivência e a reprodução da vida. Comunidade é, portanto, a partilha tanto de um modo de vida, quanto de uma terra em comum. 
Para além da interpretação do conceito, importa ainda enfatizar que os grupos humanos vivem enlaçados por um recorte tempo/espacial, na formação de um "nós" construído ao longo da história.

Devemos observar bem, quem são as pessoas que estão "na" comunidade e quem são os que realmente se consideram "da" comunidade. De um lado, podemos presenciar casos de sujeitos que tem um território e não são consideradas integrantes da comunidade. De outro, sujeitos que moram e que não possuem nenhum tipo de vínculo afetivo com o lugar. Ou ainda, sujeitos que se sentem membros, porém moram fora do seio comunitário. E finalmente, as pessoas que realmente moram, vivem e se sentem da/na comunidade.

Segundo Brandão (1995), temos neste caso a simples ação prática de habitar sem o reconhecimento dos demais membros da comunidade; o habitar sem o real sentimento de pertencimento a comunidade; o não - habitar, mas considerar-se como membro da comunidade em função dos laços passados e, o habitar territorialmente e sentimentalmente a comunidade e compartilhar o sentimento de proteção, segurança e estabilidade com a comunidade. Isso reflete os recortes espaços/temporais que perpassam o sentido de comunidade.

A diferença entre o viver "na" e ser "da" comunidade está no sentimento de pertencimento, afinidade, na relação de reciprocidade e na formação de uma identidade com o lugar. A identidade se cria pelos laços de afetividade com o território e com as pessoas, através de seus modos de vida e representações do espaço de vivência. A constituição dos espaços de vivência de um grupo dentro de uma comunidade são bastante característicos, podendo ser visualizados a partir dos seus usos, conforme quadro 1, da seguinte forma:

Quadro 1 - Usos e ocupações dos espaços

\begin{tabular}{|l|l|}
\hline \multicolumn{1}{|c|}{ ESPAÇOS } & \multicolumn{1}{c|}{ ONDE ACONTECEM } \\
\hline Geográfico & Locais de habitação, incluindo a dimensão do simbólico \\
\hline Reprodução da vida & Locais onde acontecem as práticas econômicas \\
\hline Convivência & Locais para ações do bem comum \\
\hline Instituições sociais & Locais que não são considerados da comunidade \\
\hline
\end{tabular}

Fonte: Souza, (2009).

Com efeito, podemos definir duas situações distintas. De um lado, aquilo que é originário da comunidade, ou seja, que faz parte da gramática social e linguística da comunidade. Do outro, o que vem de fora, ações e objetos que são inseridos na comunidade por algum tipo de instituição, como por exemplo, a instalação de uma escola. Devemos entender que estas duas situações são, ora mais ou menos presentes nos espaços da comunidade dependendo das características próprias de cada localidade.

Portanto, em uma primeira análise separamos o que são as bases conceituais e territoriais de uma comunidade, interpretadas como um modo interativo de vivência cotidiana, retratando formas de estar na comunidade e viver em comunidade nos diversos lugares.

\section{AS RELAÇÕES SOCIAIS EM COMUNIDADE}

A partir de agora buscamos entender como as relações sociais entre coisas e pessoas são importantes na vida em comunidade. O que realmente é necessário saber é que as relações em comunidade devem ser entendidas de duas maneiras distintas. Primeiramente, classificamos como uma relação de endo-dependência (dentro da comunidade) ou ainda uma relação de inter-dependência (entre comunidades e lugares distantes). De fato, devemos perceber que no caso da vida em comunidade as relações se dão de acordo com interesses comuns, fundados basicamente pela comunicação.

A comunicação é um dos fatores primordiais para a manutenção de condutas que vão além das gramáticas sociais. O comportamento, o agir, o vestir, o falar e ainda a lógica de comunicação 
com a natureza formam um todo. Uma "área de existência social” com formas de comportamento presentes inteiramente dentro de uma área de vivência comum bastante delimitada.

Porém, estas características atreladas aos vínculos com o passado podem ser apontadas como típicas da comunidade tradicional?

Foster (1976) caracteriza a comunidade tradicional de acordo com a idéia de uma sociedade parcial com uma cultura parcial. Esse autor considera a sociedade camponesa um segmento de classes, ou seja, está interligada, mas não é integrada. São partes da sociedade em que vivem, mas não se sentem integrantes dela. $\mathrm{O}$ termo cultura parcial seria definido pelo autor pelo que conhecemos como ideia de igualdade, com uma economia praticada para gerar uma uniformidade de capitalização.

Martins (1975) trabalha na mesma perspectiva com a idéia de produção de "excedentes" apenas para a manutenção da vida camponesa. Ainda, como preferem outros autores como Atkisson (2010), na idéia das comunidades sustentáveis, onde todos mantêm o mesmo padrão de vida e vivem da ajuda mútua.

As relações sociais que acontecem dentro de uma comunidade em grande parte estão ligadas em função dos laços de parentescos existentes, onde a "família é o centro da vida afetiva do indivíduo", Pierson (1966). Em muitos casos a própria formação da comunidade acontece em função destes laços que continuam se propagando nos tempos atuais, como auto-afirmação de grupos coesos e disseminadores de uma cultura própria, garantindo a reprodução dos saberes de geração em geração.

As visões que um pesquisador tem de uma comunidade devem abarcar os sentimentos de afetividade, os laços de parentescos, as amizades e as vizinhanças. O compadrio é outra conduta social bastante praticada na vida comunitária, sendo uma norma moral que orienta a conduta e a reciprocidade, se funda na interdependência econômica dos participantes da relação social e se alicerça na mutualidade dos interesses envolvidos, constituindo uma espécie de aliança social mais ou menos estável. A maior parte das pessoas se relaciona pelos laços consanguíneos ou de casamento, com uma cultura fortemente caracterizada pela religiosidade e por superstições.

Além dos grupos sociais temos ainda a vida comunitária, pessoas que interagem e que possuem vínculos em comum. O comportamento dos grupos é o que enlaça as pessoas, portanto o saber fazer e as redes de significados existentes entre elas devem ser analisados.

\section{AS PRÁTICAS DO FAZER}

As formas de trabalho em comunidades tradicionais também merecem destaque. Nos estudos de Meyer (1979), por exemplo, a autora destaca a formação da vida sendo constituída em função das práticas do fazer. $\mathrm{O}$ ato de plantar e cultivar a terra de forma singular traduz um modo de vida característico de povos que priorizam o trabalho familiar, a troca de dias e os mutirões como forma de reprodução. A divisão sexual do trabalho também é descrita pela autora como uma estratégia para se manterem enquanto família camponesa.

O acordo tácito, a formação de um "ethos" e uma ética baseado em um direito tradicional para uso do território se faz presente; a divisão das terras acaba não sendo prioridade, o que facilita a manutenção da família na localidade. Segundo Meyer (1979), os sítios são agrupados em linhas, onde predominam os "fortes" sobre os "fracos". Estas expressões estão relacionadas à produção da lavoura. As redes de solidariedade são capazes de articular vários sítios, sendo encarada pela autora como forma de defesa da comunidade.

Woortmann e Woortmann (1997) caracterizam a vida e o trabalho camponês com a terra de forma indissociável. Segundo eles as relações sociais, de gênero, familiares, comportamentais e espaciais engendram-se a partir da lógica interna de saberes e conhecimento da natureza. Neste caso, todo o processo produtivo é envolto por uma articulação de ações técnicas e simbólicas que perpassam a lógica de produção camponesa dos nordestinos estudados por esses autores. Portanto, "além de produzir cultivos, o trabalho produz culturas". A classificação de "forte/fraco" e "quente/ 
frio" foi utilizada por eles para identificar o entendimento dos camponeses sobre a qualidade da terra e das plantas.

Nos estudos de Araújo (2009) a autora descreve com sutileza as várias formas de ocupação e usos dos espaços para o trabalho. A beira do rio, a lagoa e a ilha são espaços de vivência, onde saber observar as regras da natureza é essencial para se produzir. As comunidades "vazanteiras" pesquisadas por ela, desenvolvem técnicas singulares de produção de acordo com o conhecimento do solo e das práticas agrícolas herdadas dos antepassados. Todas estas possibilidades e potencialidades são chamadas pela autora de "sociodinâmicas ambientais", onde os vínculos e códigos sociais são evidenciados pela ocupação do território e a sua permanência. O uso das terras em comum é uma das estratégias para a manutenção e reprodução social do grupo, distribuídas conforme apresentado no fluxograma 1, da seguinte forma:

Figura 1 - Fluxograma: Categorias de uso da terra
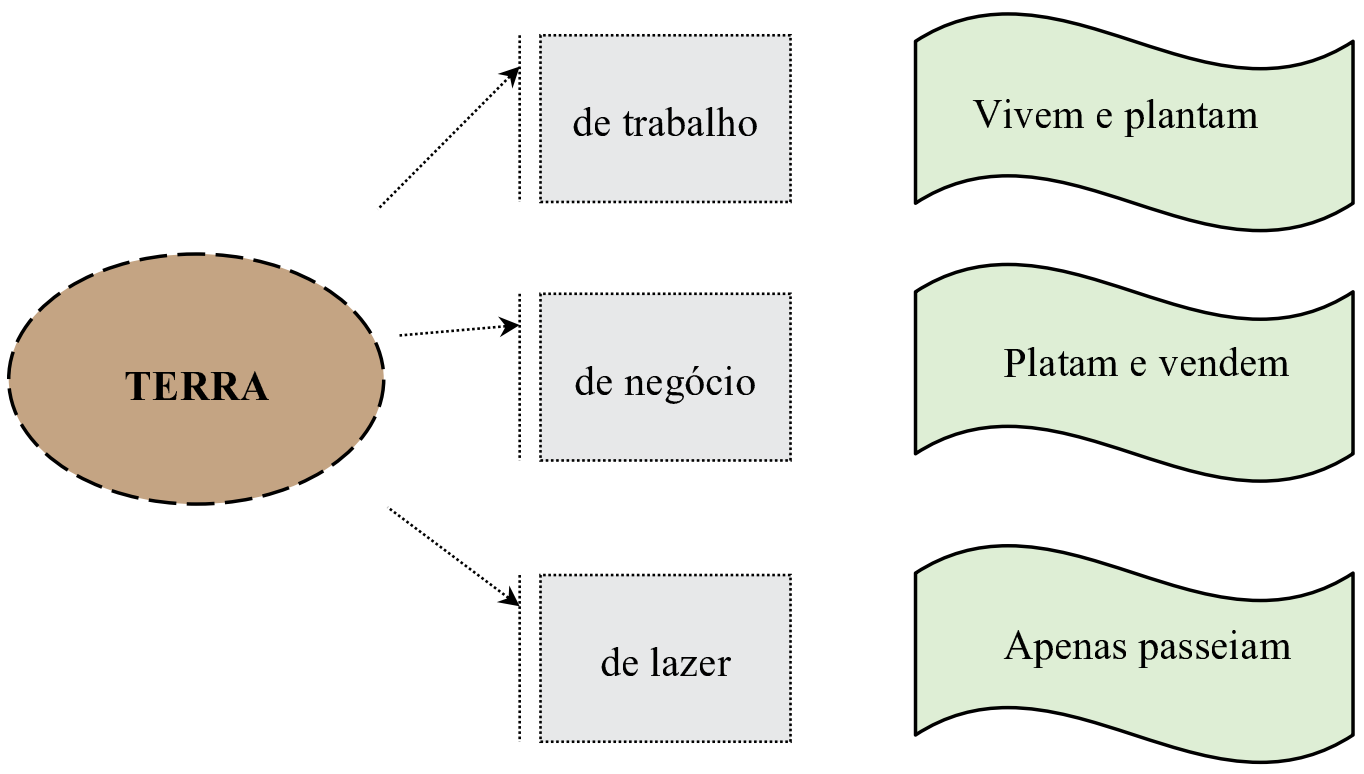

Fonte: Souza, (2009).

Esta distribuição distingue ainda duas formas diferenciadas de ocupação e produção entre "ser do lugar" versus "ser de fora". Para os que vivem no lugar, a terra é símbolo de vida e de trabalho. Dela eles retiram o sustento de sua família. Terra que lhes oferece abrigo e proteção, que oferta a água e partilha vidas. Já para os que vêm "de fora" a terra acaba sendo apenas objeto de capitalização e exploração de recursos.

Além das práticas de produção, temos ainda as regras de comportamento que estabelecem as formas de agir dentro de um grupo, criando códigos próprios de conduta.

\section{AS ÉTICAS DO AGIR}

As regras de convivência permite uma distinção na relação vivida por cada núcleo familiar. Segundo Brandão (1995) existe toda uma rede de relações comportamentais que ditam as regras de convivência e de participação dentro de uma comunidade. O fato de "viver só", na maioria dos casos, não é bem visto pelos moradores, muitos preferem dizer que moram só, mas não vivem sozinhos, estão com Deus.

A relação familiar é bastante valorizada, sendo pensada como uma teia de gestos sociais e simbólicos que tornam possíveis a convivência, ou seja, só se vive bem se estiverem na companhia da família. 
Para além da família temos as relações entre outros grupos, reunidos tanto pelas experiências como pelo prazer da convivência. São outras teias que se formam pela idade ou pelos interesses em comum, aproximando ou afastando os sexos.

O quadro 2 a seguir demonstra a movimentação das pessoas através de domínios entrelaçados, em um ciclo onde todos comunicam entre si.

Quadro 2 - Os círculos do "ser"

\begin{tabular}{|l|l|l|}
\hline \multicolumn{1}{|c|}{ CATEGORIAS } & \multicolumn{1}{c|}{ CARACTERÍSTICAS } & \multicolumn{1}{c|}{ EXEMPLO } \\
\hline Viver sozinho & "estar só" & Velhos \\
\hline Relação dual & "estar a dois" & Casal \\
\hline Grupo familiar & "estar com os meus" & Família \\
\hline Grupos de interesses & "estar entre os meus" & Time de futebol \\
\hline Grupos de idade & "estar como os como eu" & Grupos de homens \\
\hline
\end{tabular}

Fonte: Brandão, (1995) adaptação por: Souza, (2009).

A pratica da religião é algo notório nos grupos comunitários, sendo motivo da participação efetiva e do sentimento de ser "de dentro" da comunidade. Os seres em todas as suas ações práticas da vida carregam sentidos, significados e simbolizações, o "pedir pelo outro" acaba sendo um gesto de gratidão e solidariedade.

A conduta religiosa é usada para justificar as ações práticas e simbólicas que ora, se mesclam ou se separam. Em muitos casos fica evidente a persistência de ritos e crenças tradicionais adotadas como símbolos marcantes de uma localidade centrada na família e na vida comunitária.

De acordo com Brandão (1995) para os que vêm "de fora" existe uma sutil diferença entre "conviver" e "participar". Conviver significa partilhar, trocar experiências coletivas, já participar é simplesmente a ação prática para a produção de bens. "Portanto todas as pessoas que vivem em comunidade estão em algum lugar de convivência porque desejam ser e estão em algum lugar de participação porque são convidados ou convocados" Bandão, (1995, p. 160), porém, em ambos os casos as relações de afinidade são diversas.

Todos os espaços sociais de trabalho, convivência e participação, configuram situações simbólicas de afirmação de similitude e diferença. O que distingue uns dos outros é a maneira como interna e externamente relacionam o desejo da afirmação de uma e outra, na produção de identidades. (BRANDÃO, 1995, p. 166 grifos do autor).

Todas estas diferenças e similitudes são expressas pela oposição entre "modernidade" atribuída as pessoas que são "de fora", ou seja, "gentes como nós" e tradição aos "de dentro", "gentes como os nossos".

Com isso percebemos a complexidade e a diversidade presentes em tais comunidades tradicionais, muitas vezes ocultas. Saber, por exemplo, quais são os espaços masculinos e femininos e que existe uma enorme diferença de nomeações do trabalho produtivo, são particularidades da vida cotidiana de cada comunidade. Para desvendar tais códigos e redes é preciso participar efetivamente da vida destes povos.

\section{LÓGICAS DIFERENCIADAS DO PENSAR}

Geralmente a ligação com os antepassados e às raízes históricas é fator primordial para caracterizar um lugar como tradicional, porém os tipos de comportamentos atrelados ao passado, atualmente torna-se diretamente dependente da vida moderna. Neste caso a tradicionalidade é analisada a partir das formas comportamentais de cada comunidade. 
Para tanto, como é possível distinguir uma comunidade tradicional das demais? Faris (1970) afirma que "devemos apelar para a experiência ao invés de nos limitarmos ao comportamento", dando importância para as atitudes e as organizações presentes. Portanto a essência do que ele chama de "grupo primário" está no seu caráter funcional e emocional, o que significa dizer que os fatores sociais estão intimamente relacionados ao sentimento do "nós". Cooley (1970) salienta a importância da associação e a cooperação na família, na vizinhança ou na comunidade como um todo, onde a vida é o propósito comum do grupo.

Redfield (1970) descreve duas maneiras distintas de pensar e agir. Seus estudos são baseados nas sociedades "intermediárias" que vivem um duplo mundo, entre a vida da cidade e os modos de vida primitivos. As suas reflexões foram formuladas a partir do comportamento das sociedades camponesas consideradas particulares por possuir um segmento social próprio aliado ao órgão social, ambas em equilíbrio.

As particularidades e mudanças das sociedades tradicionais devem ser consideradas, levando a dissociação dos conceitos de "sociedade", "comunidade" e "cultura".

O Caipira descrito por Cândido (2003) enquanto tradicional, vive uma vida marcada pela sujeição aos grandes proprietários. Na grande maioria são posseiros ou pequenos sitiantes que produzem apenas para a sua subsistência. Adotam um sistema de parcerias baseado na presença da família e da vizinhança. A descrição desse autor é de uma sociedade rústica que caracteriza-se pelos vínculos com a natureza, produzindo apenas os "mínimos vitais e sociais" para a sobrevivência, resistindo às mudanças sociais e lutando pelo seguimento do viver caipira.

Comparando o modo de vida tradicional, temos ainda os estudos de Queiroz (1958) em que a característica principal da comunidade por ela estudada é o convívio em um mesmo espaço de pessoas com comportamentos culturais completamente diferenciados. De um lado, os alagoanos que sobrevivem pelas relações de trabalho e solidariedade e de outro, os baianos onde vigora o individualismo, não sentindo-se como um todo e vivendo uma cultura totalmente urbana.

Ambas sobrevivem harmonicamente no mesmo espaço geográfico, cada uma com formas próprias de sobrevivência e adaptações ao meio. Destacando a singularidade do comportamento alagoano, que insiste em se afirmarem por suas formas simples de convívio e pelos laços de parentescos e de vizinhanças existentes.

Stavenhagen (1979), afirma que o tradicionalismo tende a ser cada vez mais substituído pelo moderno, atribuindo esta mudança à predominância cada vez mais acentuada do modo de vida urbano industrial. As pessoas do campo estão a cada dia migrando para as cidades e deixando de lado a vida do "ritmo lento" para uma vida do "ritmo rápido". Estas mudanças nas estruturas sociais implicam em múltiplos conflitos entre sistemas de valores.

Foster (1976) aponta as necessidades de um viver camponês na comunidade de Tzintzuntzan no México, mostrando as dificuldades e adaptações sofridas pelas pessoas que tem constantemente contato com a vida da cidade. $\mathrm{O}$ autor retrata o sentimento de igualdade, geralmente ligado às raízes históricas enquanto comunidade tradicional, totalmente atrelado ao passado, porém dependente da vida moderna.

Costa (1996) descreve a maneira peculiar de vivência social das pessoas da região Nortemineira, que segundo o autor, construiu uma identidade própria com o lugar e uma cultura singular chamada de "sertaneja". As evidências dos processos de ruptura sofridos pelos povos retratados pelo autor são principalmente em função do acelerado processo de modernização do campo e a recente necessidade de vinculação às relações urbanas. Portanto esta cultura vive, em níveis diferenciados, de um lado o viver tradicional e de outro o mundo urbano.

A grande tendência da sociedade globalizada é adapatar-se aos avanços da modernização e da vida urbana. Todavia devemos levar em consideração as particularidades e resistências existentes. Sabemos ainda, que o "novo" e o "velho" vivem em complementaridade, sofrendo vários arranjos e adaptações para manterem-se enquanto tais. 
Tanto a comunidade como a tradicionalidade devem ser analisadas pelas suas diversidades e peculiaridades. Elas acabam em muitos casos sendo pouco evidenciadas empiricamente e generalizadas conceitualmente. Apesar dos diferentes modos de comportamento, todas as relações vividas em comunidade, baseadas na tradicionalidade, carregam o sentimento do "ser", "estar" e "permanecer" no lugar. O sentimento do "nós" resultando no "caldeamento" de interações, saberes e fazeres diferenciados presente nas comunidade tradicionais.

O fluxograma 2 abaixo sintetiza as principais abordagens acerca das comunidades tradicionais, visualizando nuances diferenciadas que podem ser trabalhadas conceitualmente.

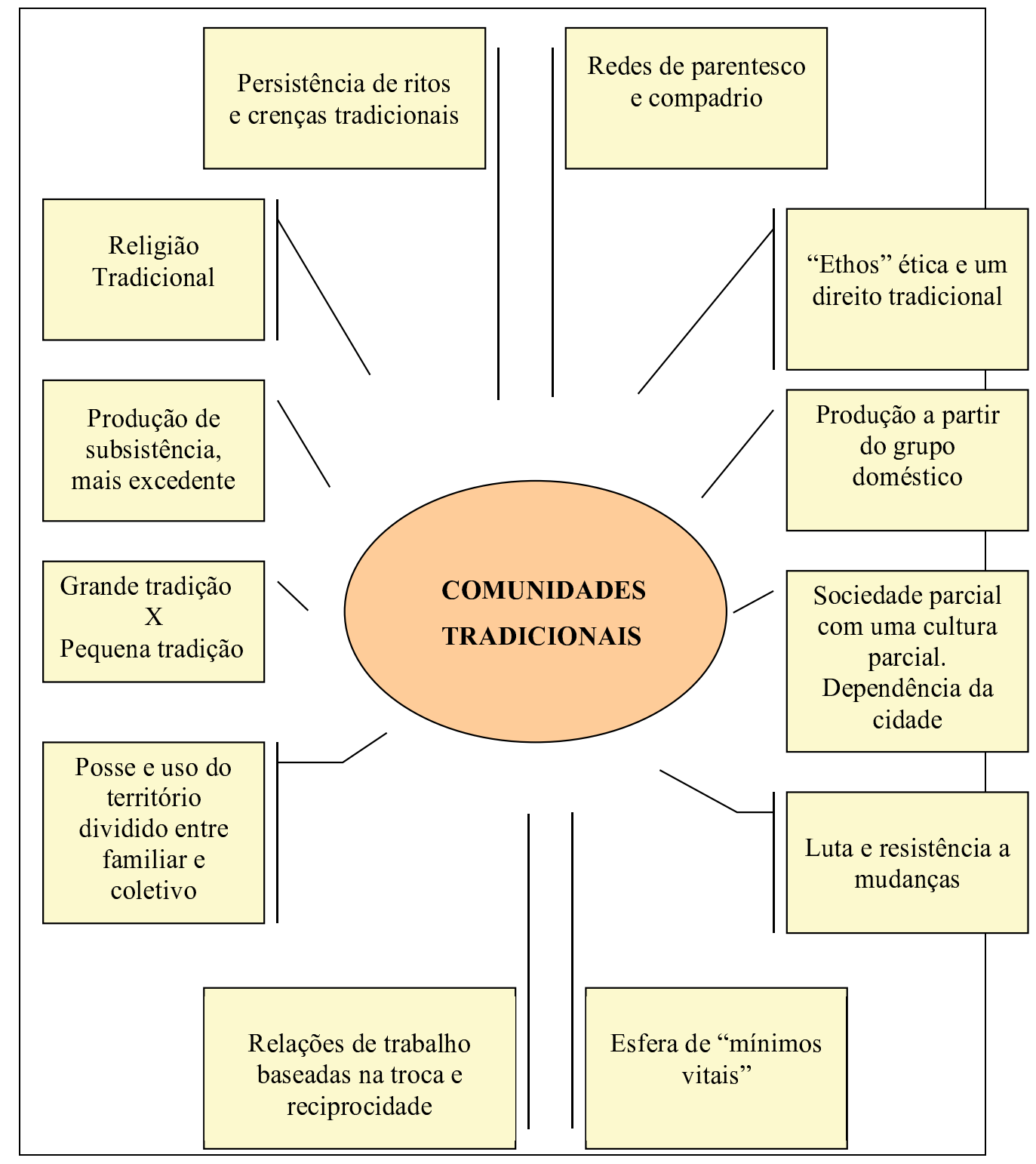

Figura 2 - Fluxograma: Representação das Comunidades Tradicionais Fonte: Souza, (2009).

Apesar das pesquisas individuais de cada autor, todas elas retratam as relações tradicionais com o passado, mas que também atravessam dimensões de uma cultura em processo, capaz de adaptar-se aos movimentos, as modificações ou como prefere Canclini (2003) as hibridizações. Apesar de todos estes processos, devemos salientar que as comunidades e as culturas tradicionais não estão tão estratificadas como muitos imaginam. Devemos entendê-las diacronicamente, perguntando sempre o que está sendo modificado e observar os processos modernizantes que transformam a utilização dos espaços preenchidos pelas comunidades. 


\section{CONSIDERAÇÕES FINAIS}

Partindo das reflexões teóricas de alguns autores trabalhados neste texto, apesar de estudos diferenciados, das enormes distâncias entre cada comunidade, épocas diferentes dos escritos e dos diferentes olhares de cada pesquisador, o que notamos foi uma estreita relação entre todos eles.

Sabemos que dos mais simples aos mais complexos estudos, todos procuram entender as comunidades tradicionais pela vida cotidiana, pelos seus espaços, pelos seus lugares e pelos seus tempos de convivência e interação, destinam-se a sujeitos que se entrecruzam e se distinguem. São tempos, espaços e lugares socioculturais reservados ao trabalho produtivo, à reprodução da unidade familiar e do grupo social. Geralmente retratam momentos e lugares do nascer, crescer, viver, plantar, colher, enfim do conviver e do aprender a ensinar.

As diferentes visões sobre comunidades nos instigam a pensar sobre o foco de cada uma delas. Neyer (1979) descreve com precisão a composição social das pessoas, que buscam por meio do trabalho uma forma de sobrevivência. Brandão (1995) fixa o seu olhar na composição do "nós", nas cumplicidades existentes, trabalhando na partilha da vida social e não apenas do viver de cada um. Algumas interpretações como a de Costa (1997) vão além dos estudos de classes ou de reproduções de poderes, visam interpretar as regras próprias criadas pelos moradores para reproduzir uma cultura com laços na tradicionalidade.

Não importando portanto, associar ou diferenciar tais estudos. O valor científico de cada um deles é altamente significativo, tais combinações tanto da composição social de comunidade como na partilha de um saber tradicional, ganham sentido e significado por serem estudos das comunidades camponesas tradicionais.

Todas essas reflexões vêm reafirmar a autonomia que as comunidades tradicionais têm para a manutenção do saber tradicional e da relação harmônica com a natureza. A persistência e resistência de cada um desses povos ao "novo" reafirma a luta pela manutenção de saberes, refletidos na cultura tradicional.

Seja o "caipira" retratado por Cândido (2003), os "catuçabas" estudados por Brandão (1995), os "sertanejos" analisados por Costa (1997), os "caiçaras" pesquisados por Mussolini (1980) ou os "vazanteiros" estudados por Araújo (2009), todos eles têm ensinamentos riquíssimos que ao longo dos tempos e em espaços diferenciados vem sendo capturados por pesquisadores empenhados em descrever um viver, que em muitos casos não existe mais, mas que precisam ser evidenciados.

As comunidades tradicionais ainda sobrevivem em função da formação de suas bases na organização sociocultural. Elas se mantêm pela formação de uma identidade pautada nos laços de solidariedade, alianças e também de conflitos. Todo este complexo envolvendo as relações sociais, políticas, econômicas, religiosas e culturais nos permite uma diversidade para se trabalhar o conceito, não de forma fragmentada, mas sim, integrada, produzindo "lógicas diferenciadas" envolvidas por um saber característico de cada local estudado.

\section{REFERÊNCIA BIBLIOGRÁFICA}

ARAÚJO, Elisa Cotta de. Nas margens do São Francisco: sociodinâmicas ambientais, expropriação territorial e afirmação ética do Quilombo da Lapinha e dos Vazanteiros do Pau de Légua. Montes Claros, PPGDS, 2009, 252f. Dissertação de (mestrado em Desenvolvimento Social). Departamento de Ciências Sociais, Unimontes, 2009.

ATKISSON, Alan. Desenvolvimento de Indicadores de Comunidades Sustentáveis - Lições do Seatle Sustentável. Centro de Referência em Gestão Ambiental para Assentamentos Humanos, Universidade Livre do Meio Ambiente UNILIVRE. Disponível em: <http://www.unilivre.org.br>, acesso em maio de 2010.

CANCLINI, Néstor Garcia. Culturas híbridas: estratégias para entrar e sair da modernidade. São Paulo: EDUSP, 2003. 
CÂNDIDO, Antônio. Os Parceiros do rio Bonito: estudo sobre o caipira paulista e a transformação dos meios de vida. 10 ed. São Paulo: Editora 34, 2003. (coleção Espírito Crítico).

COOLEY, Charles H. "Grupos primários". In: PIERSON, Donald. Estudos da organização social. TOMO II. Leituras de Sociologia e Antropologia Social. São Paulo: Martins, 1970.

COSTA, João Batista de Almeida. Cultura Sertaneja: a conjugação de lógicas diferenciadas. In: SANTOS, Gilmar Ribeiro dos (Org.). Trabalho, Cultura e Sociedades no Norte/Nordeste de Minas: Considerações a partir das Ciências Sociais. Montes Claros: Best Comunicações e Markting, 1997.

FARIS, Ellsworth. "Grupos primários": essência e acidente. In: PIERSON, Donald. Estudos da organização social. TOMO II. Leituras de Sociologia e Antropologia Social. São Paulo: Martins, 1970.

FOSTER, George M. Tzintzuntzan. Los campesinos mexicanos en un mundo en cambio. México: Fundo da cultura econômica, 1976.

FREYER, Hans. Comunidade e sociedade como estruturas histórico-sociais. In: FERNANDES, Florestan. Comunidade e Sociedade: Leituras sobre Problemas Conceituais, Metodológicos e de Aplicação. São Paulo: Nacional e Edusp, 1973.

MACLVER, Robert Morrison; PAGE, Charles Harrison. Comunidade e sociedade como níveis de organização da vida social. In: FERNANDES, Florestan. Comunidade e Sociedade: Leituras sobre Problemas Conceituais, Metodológicos e de Aplicação. São Paulo: Nacional e Edusp, 1973.

MARTINS, José de Souza Martins. Capitalismo e tradicionalismo (estudos sobre as contradições da sociedade agrária no Brasil). São Paulo: Pioneira, 1975.

MARTINS, José de Souza; FORACCHI, Marialice Mencarini. Sociologia e Sociedade. (Leituras de introdução à Sociologia). 21 ed. Rio de Janeiro: Livros Técnicos e Científicos Editora S. A., 1999

MAYER, Doris Rinaldi. A terra do santo e o mundo dos engenhos: estudo de uma comunidade rural nordestina. Rio de Janeiro: Paz e Terra, 1979. (Série Estudos sobre o Nordeste; v. 9).

MUSSOLINI, Gioconda; CARONE, Edgard. Ensaios de antropologia indígena e caiçara. Rio de Janeiro: Paz e Terra, 1980.

PARK, Robert Ezra; BURGESS, Ernest Watson. Comunidade e sociedade como conceitos analíticos. In: FERNANDES, Florestan. Comunidade e Sociedade: Leituras sobre Problemas Conceituais, Metodológicos e de Aplicação. São Paulo: Nacional e Edusp, 1973.

PIERSON, Donald. Cruz das Almas. São Paulo: José Olympio / Edusp, 1966.

QUEIROZ, Maria Isaura Pereira de. Sociologia e Folclore: a dança de São Gonçalo num povoado baiano. Salvador: Fundação para o desenvolvimento da Ciência na Bahia, 1958.

RAMOS, Jarbas Siqueira. Os Catopês de Bocaiúva: um debate sobre comunidade. In: Encontro Regional dos Povos do Cerrado, 5, 2009, Pirapora. Anais... Pirapora: Unimontes, 2009.

REDFIELD, Robert. A "sociedade de Folk" e a cultura. In: PIERSON, Donald. Estudos da organização social. TOMO II. Leituras de Sociologia e Antropologia Social. São Paulo: Martins, 1970.

STAVENHAGEN, Rodolfo. Classes rurais na sociedade agrícola. São Paulo: Edições Loyola, 1979.

TONNIES, Ferdinand. Comunidade e sociedade como entidade típico-ideais. In: FERNANDES, Florestan. Comunidade e Sociedade: Leituras sobre Problemas Conceituais, Metodológicos e de Aplicação. São Paulo: Nacional e Edusp, 1973.

WEBER, Max. Comunidade e sociedade como estruturas de socialização. In: FERNANDES, Florestan. Comunidade e Sociedade: Leituras sobre Problemas Conceituais, Metodológicos e de Aplicação. São Paulo: Nacional e Edusp, 1973.

WIRTH, Louis. Delineamento e problemas da comunidade. In: FERNANDES, Florestan. Comunidade e Sociedade: Leituras sobre Problemas Conceituais, Metodológicos e de Aplicação. São Paulo: Nacional e Edusp, 1973.

WOORTMANN, Ellen. Fensterseifer. O sítio camponês. In: Anuário Antropológico. Rio de Janeiro: Editora Tempo Brasileiro, n. 81, 1983. 
WOORTMANN, Ellen Fensterseifer; WOORTMANN, Klaas. O trabalho da terra: a lógica e a simbólica da lavoura camponesa. Brasília: Editora Universidade de Brasília, 1997.

WOORTMANN, Klaas. "Com parente não se neguceia". O campesinato como ordem social. In: Anuário Antropológico. Brasília: Editora Universidade de Brasília, n. 87, 1990.

Trabalho enviado em setembro de 2012 Trabalho aceito em outubro de 2012 